\title{
Controlled oxidative etching of gold nanorods revealed through in-situ liquid cell electron microscopy
}

\author{
Wen Wang ${ }^{1,2}$, Tao Xu ${ }^{1 *}$, Tingting Bai ${ }^{3}$, Chao Zhu ${ }^{1}$, Qiubo Zhang ${ }^{1}$, Hongtao Zhang ${ }^{1}$, Hui Zhang ${ }^{1}$, \\ Zhirui Guo ${ }^{3}$, Haimei Zheng ${ }^{2,4^{*}}$ and Litao Sun ${ }^{1^{*}}$
}

\begin{abstract}
Oxidative etching can be a powerful approach to modify the morphology of nanoscale materials for various applications. Unveiling of the etching mechanisms and morphological evolution during etching is critical. Using the liquid cell transmission electron microscopy, we investigate the etching behavior of gold nanorods under different electron beam dose rates: case $\mathrm{I}, 3.5 \times 10^{9} \mathrm{~Gy} \mathrm{~s}^{-1}$; case II, $1.5 \times 10^{10} \mathrm{~Gy} \mathrm{~s}^{-1}$; case III, $4.5 \times 10^{10} \mathrm{~Gy} \mathrm{~s}^{-1}$. The Au nanorod develops facets at the tips (case I) or adopts a transit ellipsoid shape and eventually dissolves (case II), depending on the dose rate. The rapid etching under an even higher dose rate (case III) may lead to the formation of $\mathrm{Au}^{3+}$ ion-rich intermediates around the nanorod, which further accelerates the lateral etching and unexpectedly increases the aspect ratio of the nanorod. Our quantitative analysis shows that the critical size of the nanorod, below which the etching rate increases significantly with the reduction of nanorod size, may vary subject to the degree that the system is away from equilibrium. These results provide significant insights into the oxidative etching mechanisms and shed light on the rational design and synthesis of nanostructures.
\end{abstract}

Keywords: in-situ liquid transmission electron microscope, oxidative etching, etching mechanism, electron dose rate, gold

\section{INTRODUCTION}

Nanoscale materials have received great attention in the past two decades due to their various applications, such as medicine, energy conversion and storage, electronics, photonics, and optoelectronics [1-5]. Since the properties of nanostructures are highly influenced by their size and shape, the controlled synthesis of nanostructures has been a significant topic [6-8]. The oxidative etching is an effective approach to the precise control of nanocrystal nucleation and growth at the atomic level. Studies have shown that oxidative etching can modify the nanocrystal morphology and structure by selectively removing the surface atoms $[9,10]$. An understanding of the etching mechanisms at nanoscale is crucial for the controlled synthesis of nanomaterials as well as for improving the performance of nanocrystal-based devices.

There have been many studies on etching behaviors of nanomaterials using both ex-situ and in-situ methods. The etching mechanisms of various nanocrystals have been revealed. For example, the halide ions can trigger oxidative etching of gold nanorods by effectively reducing the electron potential $[11,12]$, cetyltrimethylammonium bromide $(\mathrm{CTAB})$ can be selectively adsorbed on certain facets of a nanocrystal, resulting in the anisotropic etching [13], shape-dependent etching kinetics [14], and kinetically driven nanocrystal morphology evolution $[15,16]$. However, there are limited systematic studies that can directly compare the kinetics and pathways of nanostructure etching under controlled etching conditions.

Here, we use in-situ liquid cell transmission electron microscopy (TEM) to study the etching of Au nanorods by systematically changing the etching rate. It allows for capturing the intermediates and unveiling the underline mechanisms. The etching of Au nanorods is controlled by electron beam irradiation with various electron beam dose rates. Our results show that the etching rates and the

\footnotetext{
${ }^{1}$ SEU-FEI Nano-Pico Center, Key Lab of MEMS of Ministry of Education, Southeast University, Nanjing 210096, China

${ }^{2}$ Materials Sciences Division, Lawrence Berkeley National Laboratory, Berkeley, CA 94720, USA

${ }^{3}$ Department of Geriatrics, The Second Affiliated Hospital, Key Laboratory for Aging \& Disease, Nanjing Medical University, Nanjing 210011, China

${ }^{4}$ Department of Materials Science and Engineering, University of California, Berkeley, California 94720, USA

* Corresponding authors (emails: xt@seu.edu.cn (Xu T); hmzheng@lbl.gov (Zheng H); slt@seu.edu.cn (Sun L))
} 
morphology evolution of Au nanorods change drastically when the electron dose rate alters. Based on our quantitative analysis, we further discuss both thermodynamic and kinetic factors affecting the etching rate and morphology evolution.

\section{EXPERIMENTAL SECTION}

\section{Preparation of liquid cell samples}

The $\mathrm{Au}$ nanorods used in this work were synthesized according to a seed-mediated method [17]. The sizes of the nanorods are $70-80 \mathrm{~nm}$ long and $10-20 \mathrm{~nm}$ in diameter. Before the in-situ experiment, the nanorods were washed three times with distilled (DI) water to remove the surface capping ligands. The reaction solution was prepared by mixing an aqueous solution of $\mathrm{Au}$ nanorods $\left(50 \mu \mathrm{g} \mathrm{mL}^{-1}\right)$ and hydrobromic acid $\left(1 \mathrm{mmol} \mathrm{L}^{-1}\right)(2: 1$, $v / v)$. A microdroplet $(2.5 \mu \mathrm{L})$ of the reaction solution was sandwiched between two carbon films, and the cell was placed for more than $3 \mathrm{~h}$ before loading into the TEM (Figs S1, S2).

\section{In-situ TEM}

In-situ TEM observation was carried out using an FEI Tecnai 20 transmission electron microscope (USA) operated at $200 \mathrm{kV}$ and an FEI Titan 80-300 (USA) with Cscorrector operated at $300 \mathrm{kV}$. We systematically changed the etching condition. Several parameters may play a role, such as the acceleration voltage, electron current density and the cross-section of the interaction of high energy electrons with the sample. Here, we used three electron beam dose rates: case I, $3.5 \times 10^{9} \mathrm{~Gy} \mathrm{~s}^{-1}$; case II, $1.5 \times 10^{10} \mathrm{~Gy} \mathrm{~s}^{-1}$; case III, $4.5 \times 10^{10} \mathrm{~Gy} \mathrm{~s}^{-1}$ by controlling the acceleration voltage and current density in the experiments. We examined the distinctive intermediates and the evolution of nanorods during the etching process. And, the unit of Gray (Gy), defined as the adsorption of one joule of energy per kilogram of water, was used to describe electron beam irradiation effects and the dose rates.

\section{RESULTS AND DISCUSSION}

The etching of Au nanorods is triggered by electron beam irradiation. When an aqueous solution is exposed to the high energy electron beam, the electrolysis of water may generate various species, including hydrated (solvated) electrons $\mathrm{e}_{\mathrm{h}}{ }^{-}$, hydrogen radical ${ }^{\circ} \mathrm{H}$, hydroxyl radical ${ }^{\circ} \mathrm{OH}$, and $\mathrm{H}_{2}$ [18]. These species can participate in further reactions, yielding more complex products, such as $\mathrm{H}_{2} \mathrm{O}_{2}$, $\cdot \mathrm{HO}_{2}$, and $\mathrm{H}_{3} \mathrm{O}^{+}$. The strong oxidative species among these radiolysis reactants, such as ${ }^{\circ} \mathrm{OH},{ }^{\circ} \mathrm{HO}_{2}$, and $\mathrm{H}_{2} \mathrm{O}_{2}$, react with $\mathrm{Au}$ nanorods and turn $\mathrm{Au}$ into $\mathrm{Au}^{3+}$ ions. The presence of $\mathrm{Br}^{-}$ions may effectively reduce the electron potential of $\mathrm{Au}^{3+}$ ions by forming $\left[\mathrm{AuBr}_{4}\right]^{-}$, which further accelerates the etching of $\mathrm{Au}$ nanorods [13]. It has been reported that the concentration of the oxidizing species increases when the incident electron flux and average kinetic energy of electrons are higher [18]. Therefore, the dose rate reflecting the radiation effects of incident electrons can be used to control the etching kinetics of $\mathrm{Au}$ nanorods. We use Gy to describe the radiation effect of electron beam. It considers the influence from both electron energy and incident electron flux upon the thin liquid film. Here, we compare the Au nanorod etching processes under three electron dose rates: case I, $3.5 \times 10^{9} \mathrm{~Gy} \mathrm{~s}^{-1}$; case II, $1.5 \times 10^{10} \mathrm{~Gy} \mathrm{~s}^{-1}$; case III, $4.5 \times 10^{10} \mathrm{~Gy} \mathrm{~s}^{-1}$. More electron dose estimation and radiolysis have been provided in the Supplementary information.

Under an electron dose rate of $3.5 \times 10^{9} \mathrm{~Gy} \mathrm{~s}^{-1}$ (case I), the nanorod is etched slowly and the eventually facets are developed at the tips (Fig. 1a and Movie S1). The presence of low energy facets suggests that the surface atoms can rearrange to minimize the energy. Therefore, the morphological evolution of nanorod is under conditions close to the thermodynamic equilibrium [19].

When the electron beam dose rate increases, the nanorod is etched much faster and undergoes different morphological evolution. Under a dose rate of $1.5 \times 10^{10} \mathrm{~Gy} \mathrm{~s}^{-1}$ (case II), the Au nanorod becomes an ellipsoid, as shown in the sequential images (Fig. 1b) and the corresponding contour plots (Fig. 1c; also see Movie S2). The changes of longitudinal etching rate and the tip curvature as a function of time are plotted (see Fig. 1d; the lateral etching rate is not plotted). Apparently, the material at the tip is removed faster than that on the side. As the nanorod tip becomes sharper with time, the longitudinal etching rate increases. This is consistent with the curvature-selective etching in other reports $[13,16,20]$. It is also noted that the surface relaxation is slower than etching, therefore the nanorod undergoes a non-equilibrium etching process. In addition, no obvious precipitation is observed around the nanorod during etching. This suggests that the Au ions from etching diffuse away through the solution.

Interestingly, when the electron dose rate is further increased to $4.5 \times 10^{10} \mathrm{~Gy} \mathrm{~s}^{-1}$ (case III), the nanorod etching shares differences as well as similarities with case II. First, the nanorod becomes ellipsoidal and eventually disappears similar to case II (Fig. 1e and Movie S3). And 


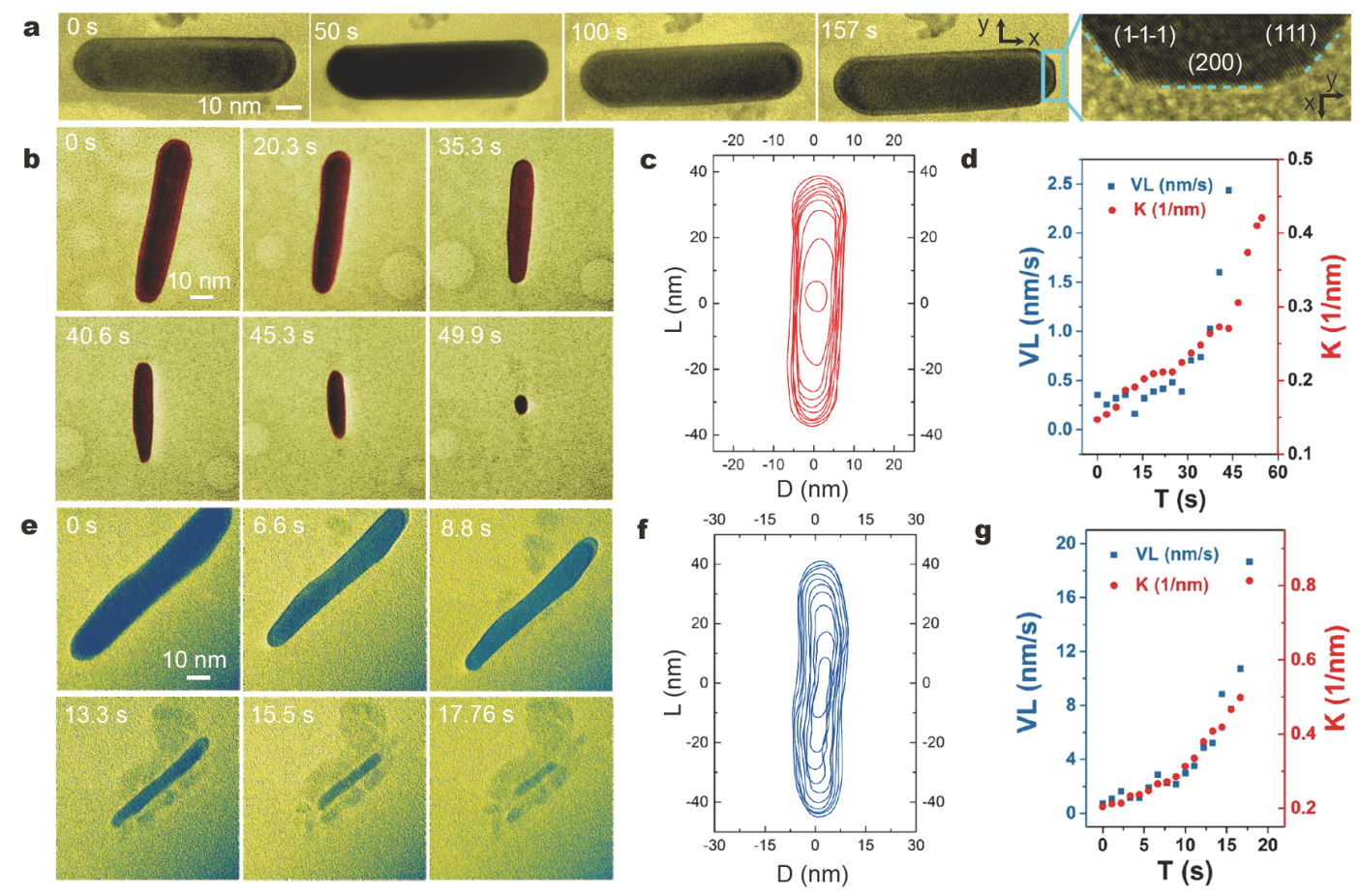

Figure 1 Etching of Au nanorods under different electron dose rates. (a) TEM images in real time show the facets development of a nanorod under the dose rate of $3.5 \times 10^{9} \mathrm{~Gy} \mathrm{~s}^{-1}$. (b, c) Sequential TEM images and the corresponding contour show the morphology evolution of a nanorod under the dose rate of $1.5 \times 10^{10} \mathrm{~Gy} \mathrm{~s}^{-1}$. (d) Plot of the longitudinal etching rate $V(\mathrm{~L})$ and the tip curvature $K$ of the nanorod as a function of time under the dose rate of $1.5 \times 10^{10} \mathrm{~Gy} \mathrm{~s}^{-1}$. (e, f) Sequential TEM images and the corresponding contour show the morphology evolution of a nanorod under the dose rate of $4.5 \times 10^{10} \mathrm{~Gy} \mathrm{~s}^{-1}$. (g) Plot of the longitudinal etching rate $V(\mathrm{~L})$ and the tip curvature $K$ of the nanorod as a function of time under the dose rate of $4.5 \times 10^{10} \mathrm{~Gy} \mathrm{~s}^{-1}$. Contour lines are spaced in time by $4 \mathrm{~s}$ in (c) and $2 \mathrm{~s}$ in (f).

the longitudinal etching rate is correlated to the curvature of the tip, which gradually increases as etching progresses (Fig. 1g). Second, the Au nanorod intermediates are slender with a higher aspect ratio in case III (Fig. 1e, f) than that in case II. And, more significantly, a "blurry shell" is developed and it further grows. When the nanorod is completely etched, the shell gradually disappears as well.

We further characterized the "blurry shell" around the nanorod during etching. Fig. 2a shows the formation and expansion of the shell. The intensity profile of the selected rectangle area in Fig. $2 \mathrm{~b}$ consists of three regions. The middle region corresponds to the nanorod, while its adjacent region corresponds to the "blurry shell". Energy dispersive X-ray spectroscopy (EDS) elemental map illustrates that the "blurry shell" contains Au (Fig. 2c). As etching proceeds, the "blurry shell" expands and $\mathrm{Au}$ nanoclusters can be found. The $\mathrm{Au}$ nanoclusters precipitate and dissolve repeatedly [21]. The "blurry shell" appears to be an amorphous dense liquid. Considering $\mathrm{H}_{2} \mathrm{O}_{2}$ and ${ }^{\circ} \mathrm{OH}$ are the main etching species formed through the radiolysis of water [18] (Table S1), Au na- norods can be etched into $\mathrm{Au}^{3+}$ ions by these strong oxidizing agents [22]. Under higher electron dose rates, the nanorod dissolves faster, resulting in a higher concentration of etching products (e.g., $\mathrm{Au}^{3+}$ ions). $\mathrm{AuBr}_{3}$ crystalline phases can be identified in the "blurry shell" under the extended electron beam irradiation, as shown in the high resolution TEM (HRTEM) images (Fig. 2d and Fig. S3),

Quantitative analysis of the etching kinetics under these three etching conditions is illustrated in Fig. 3. In case I, the length $(L)$, diameter $(D)$, and aspect ratio of the nanorod almost keep constant. In cases II and III, changes in length present a similar trend, but the etching rate is higher under a higher dose rate. In order to eliminate the effect of the initial sizes $\left(L_{0}\right.$ and $\left.D_{0}\right)$ of the nanorods, we also plot $L / L_{0}$ and $D / D_{0}$ as a function of time, which shows similar trend with $L$ and $D$ (Fig. S4). It is clear that, the changes in the aspect ratio over time in cases II and III are significantly different. In case II, the aspect ratio almost keeps constant at first and then drops quickly. However, under a higher dose rate in case III, the aspect ratio of the nanorod increases by $55 \%$ in the first 
a
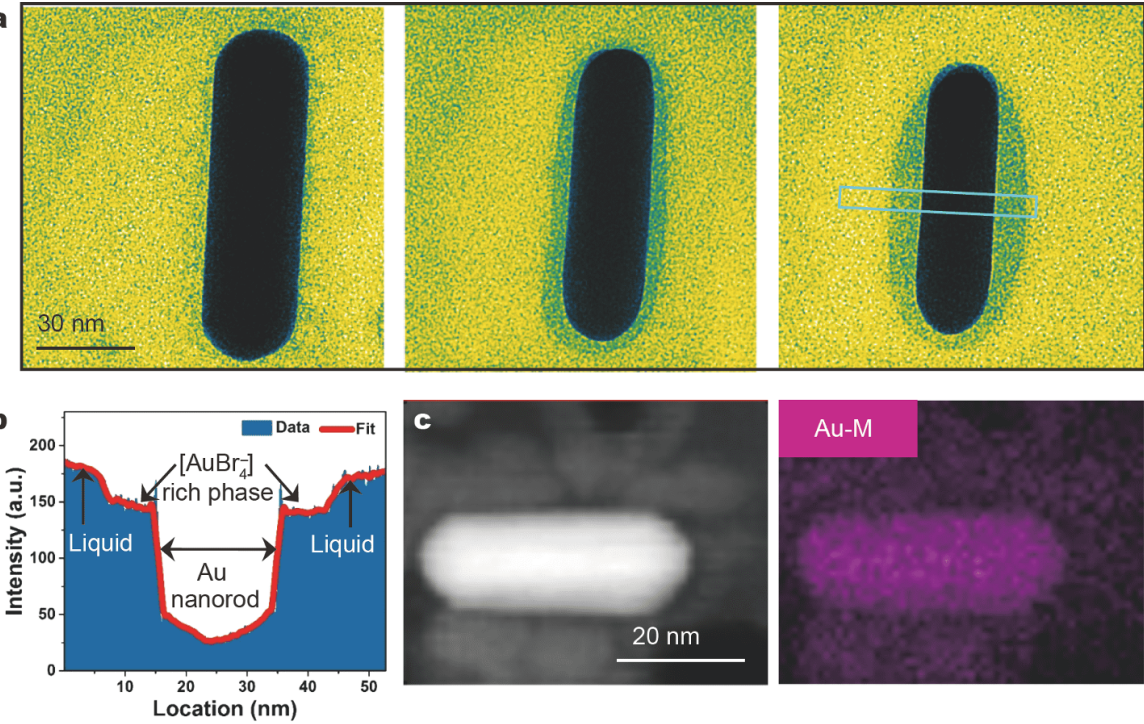

C

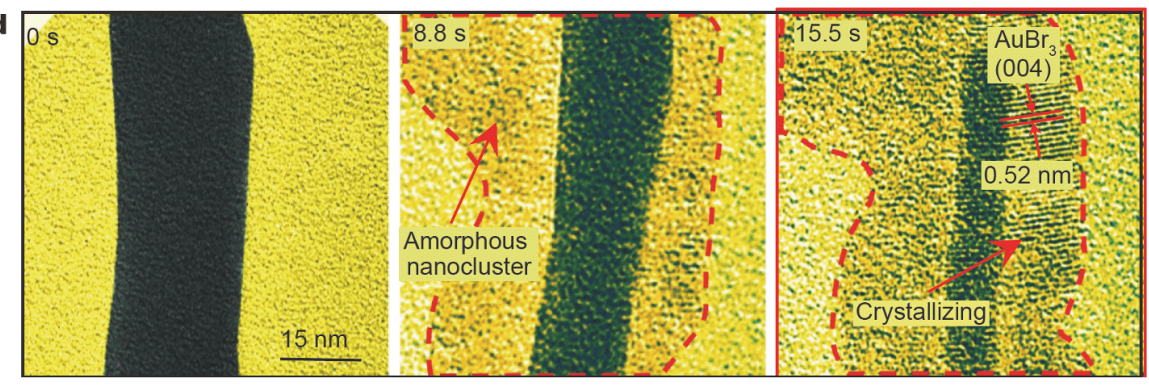

Figure 2 The formation and growth of the $\left[\mathrm{AuBr}_{4}\right]^{-}$-rich blurry shell. (a) TEM images illustrate the formation process and growth of [AuBr $]_{4}^{-}$-rich blurry shell. (b) Intensity profile across a dissolving area as shown in (a). (c) Scanning transmission electron microscopy (STEM)-EDS elemental mapping reveals $\mathrm{Au}$ around the nanorod. (d) Sequential HRTEM images during etching of $\mathrm{Au}$ nanorod illustrate the crystallization of $\mathrm{AuBr}_{3}$.

$14.43 \mathrm{~s}$. It indicates that the increase of lateral etching rate under a higher dose rate is more pronounced than in the longitudinal direction. The nanorods with different initial sizes present similar etching kinetics (Figs S5, S6), which also demonstrates that the effect of the initial size is insignificant. The increase in the aspect ratio may be attributed to the change of the oxidizing environment caused by the accumulation of $\mathrm{Au}^{3+}$ ions at the side of the nanorod. For instance, in the presence of $\mathrm{Br}^{-}$ions $\mathrm{Au}$ nanorods can also be oxidized by $\mathrm{Au}^{3+}$ ions [23].

By taking into account both kinetic and thermodynamic factors, the etching rate of the nanorod can be described as [24,25]:

$r=A k_{0} \exp \left(-E_{\text {app }} / R T\right) f(i) g(i)\left(1-\exp \left(\Delta G_{r} / \sigma R T\right)\right)$,

where $r$ refers to the etching rate, $A$ is the reactive surface area per unit volume of solution, $k_{0}$ is the rate constant, $E_{\text {app }}$ denotes the active energy of the etching. $f(i)$ is a function of active reaction ions in solution, $g(i)$ is a term that accounts for the catalysis/inhibition of the reaction. $\sigma$ represents Temkin's average stoichiometric coefficient. $R$ and $T$ are the gas constant and temperature in Kelvin, respectively. $\Delta G_{r}$ corresponds to the Gibbs free energy which represents the chemical driving force for the etching reaction resulting from the system deviating from equilibrium. Since $r$ is the rate of change of the dissolved ions concentration, we simply use the surface normalized etching rate to describe the etching rate along the long and short axes of the nanorod. The surface area is taken as a parameter to describe the size of nanorod.

It is clear that the dose rate controls the concentration of the oxidative species and thus the etching rate [18]. Although electron beam irradiation can raise the local temperature, the estimated temperature rise is less than several degrees centigrade $[26,27]$, which can be ignored. Under a low dose rate (case I), the Au nanorod has enough time to restructure and gradually develops facets, which further increases the $E_{\text {app }}$. The etching ultimately stops when the system reaches the equilibrium state. In case II, the nanorod shows a higher dissolving rate due to 

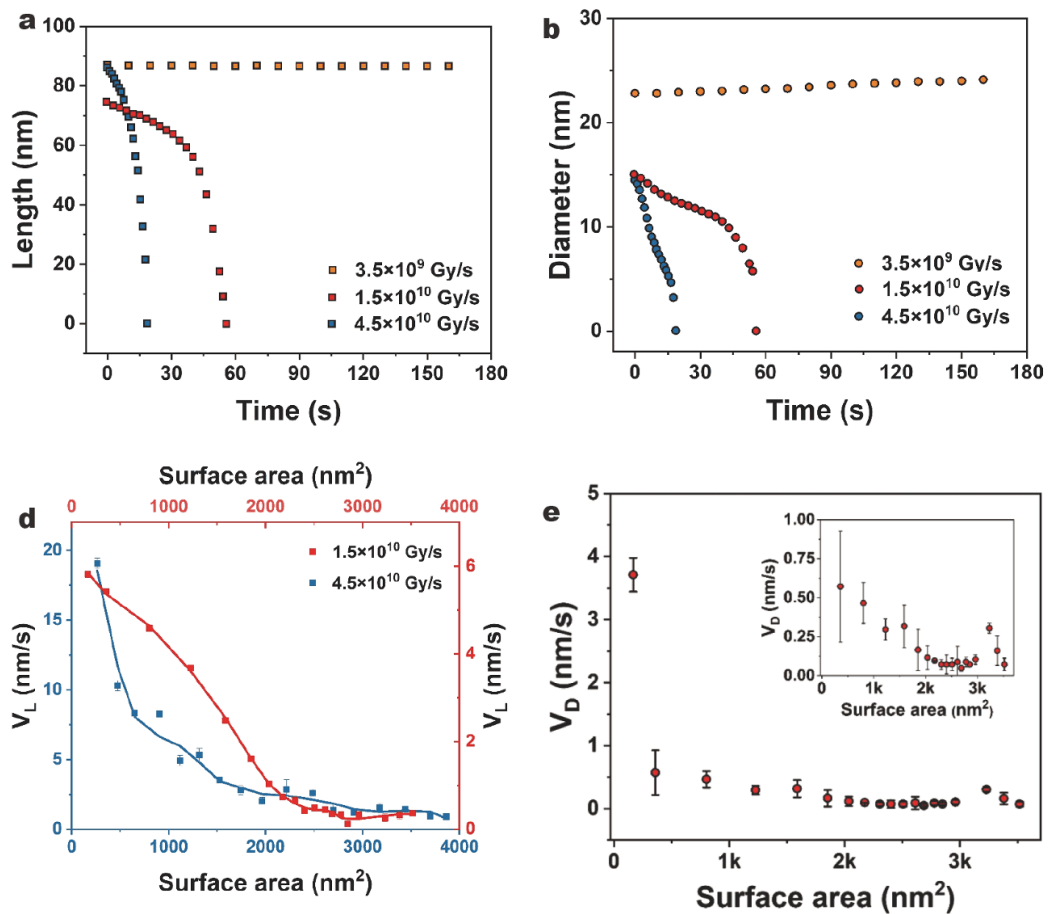

Figure 3 Quantitative analysis to compare the three mechanisms of nanorod etching. Changes in length (a), diameter (b), and aspect ratio of nanorods (c), as a function of time. (d) The longitudinal etching rate changes with nanorod surface area. (e, f) The transverse etching rates change with the nanorod surface area in cases II and III, respectively.

the higher oxidant concentration. In addition, Fig. $3 \mathrm{~d}$, e show that when the surface is less than $2000 \mathrm{~nm}^{2}$, the etching rate increases as the size of nanorod reduces. This is attributed to that the solubility of nanorod increases as the size decreases according to Gibbs-Thomson effect $[28,29]$, therefore, increasing the driving force of the etching by decreasing the $\Delta G_{r}$ [25]. Therefore, although the system is in a non-equilibrium state, thermodynamics still have effects on the etching rate. It is worth mentioning that, when the system deviates from equilibrium, the effects of $\Delta G_{r}$ increase due to the size reduction become negligible according to Equation (1). When the dose rate increases to $4.5 \times 10^{10} \mathrm{~Gy} \mathrm{~s}^{-1}$, the etching rate is increased accordingly and drives the nanorod away from the equilibrium state (Fig. 3d, f). Therefore, the size effects on the etching rate in case III are not so obvious compared with case II. The lateral etching rate roughly maintains a constant until the nanorod becomes very small (Fig. 3f).

The etching processes of $\mathrm{Au}$ nanorods under three electron dose rates are illustrated in Fig. 4. Under a low dose rate (case I: $3.5 \times 10^{9} \mathrm{~Gy} \mathrm{~s}^{-1}$ ), the nanorod is close to equilibrium state and forms more stable low-energy facets at the tips. Under a higher dose rate (case II: $1.5 \times 10^{10} \mathrm{~Gy} \mathrm{~s}^{-1}$ ), the etched products diffuse away when they are produced and no apparent $\left[\mathrm{AuBr}_{4}\right]^{-}$-rich phase is formed. In this case, the differences of etching rate in length and diameter are mainly controlled by the tip curvature, and the aspect ratio of the $\mathrm{Au}$ nanorod is constant at the beginning and it decreases at a later stage. When the dose rate is further increased (case III: $4.5 \times 10^{10} \mathrm{~Gy} \mathrm{~s}^{-1}$ ), $\mathrm{Au}^{3+}$ ions produced in the etching process tend to accumulate near the sides of nanorods to form a dense liquid, resulting in an accelerated etching in the lateral direction. Here, the aspect ratio increases to a much greater extent compared with the other two processes (also see Fig. S7). This is significant because the surface plasmon resonance (LSPR) of $\mathrm{Au}$ nanorods depends on their aspect ratio [22]. However, in most ex-situ $\mathrm{Au}$ nanorods etching experiments, the aspect ratio can only be reduced or remain a constant $[13,23]$. It is noteworthy that these different etching mechanisms are dependent solely on the electron beam conditions, which means that electron beam can be used to control the etching rate and to achieve controlled and selective etching of $\mathrm{Au}$ nanorods.

\section{CONCLUSIONS}

In conclusion, depending on the electron dose rate, the $\mathrm{Au}$ nanorod shows different etching behaviors. As the 


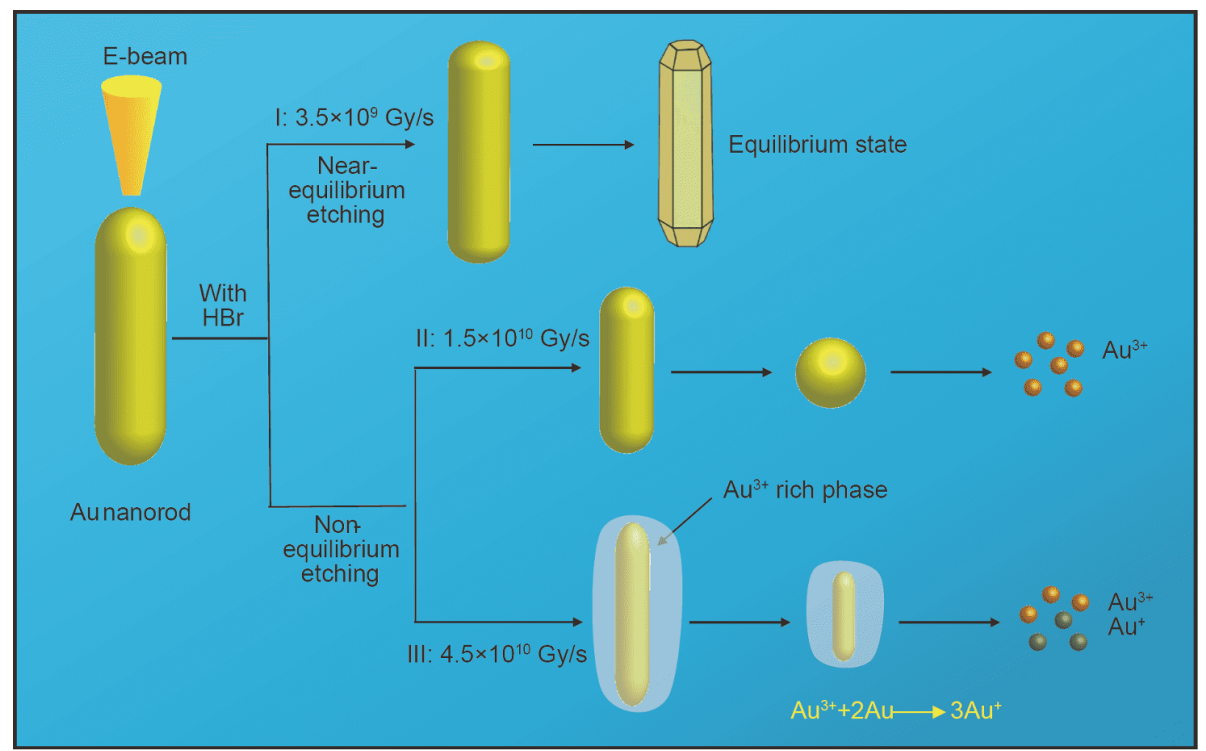

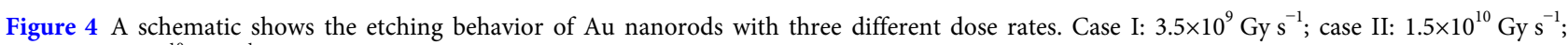
case III: $4.5 \times 10^{10} \mathrm{~Gy} \mathrm{~s}^{-1}$.

electron dose rate increases, the etching rate increases, which leads to distinctly different morphology evolution of the nanorod and the intermediates. A novel autoaccelerated etching is observed under high dose rate condition which leads to a significant increase in aspect ratio of $\mathrm{Au}$ nanorod. In addition, the nanorods show a greater etching rate as the size decreases due to the increased solubility. However, when the overall etching rate increases under a larger dose rate, the effects of size on etching rate become less pronounced. This study demonstrates the unique advantages of in-situ liquid cell TEM in revealing the mechanisms of chemical reactions in liquids. Our understanding of nanoscale etching mechanisms may assist future controlled synthesis and applications of nanostructures.

\section{Received 3 March 2020; accepted 7 April 2020;} published online 29 May 2020

1 Zhang A, Lieber M. Nano-bioelectronics. Chem Rev, 2016, 116: 215-257

2 Liang Y, Li Y, Wang H, et al. Strongly coupled inorganic/nanocarbon hybrid materials for advanced electrocatalysis. J Am Chem Soc, 2013, 135: 2013-2036

3 Prateek, Thakur VK, Gupta RK. Recent progress on ferroelectric polymer-based nanocomposites for high energy density capacitors: synthesis, dielectric properties, and future aspects. Chem Rev, 2016, 116: 4260-4317

4 Amjadi M, Kyung KU, Park I, et al. Stretchable, skin-mountable, and wearable strain sensors and their potential applications: a review. Adv Funct Mater, 2016, 26: 1678-1698

5 Koppens FHL, Mueller T, Avouris P, et al. Photodetectors based on graphene, other two-dimensional materials and hybrid systems. Nat Nanotech, 2014, 9: 780-793

6 Fan Z, Huang X, Tan C, et al. Thin metal nanostructures: synthesis, properties and applications. Chem Sci, 2015, 6: 95-111

7 Ma N, Wu FG, Zhang X, et al. Shape-dependent radiosensitization effect of gold nanostructures in cancer radiotherapy: comparison of gold nanoparticles, nanospikes, and nanorods. ACS Appl Mater Interfaces, 2017, 9: 13037-13048

8 Liu X, Zhang X, Zhu M, et al. PEGylated Au@Pt nanodendrites as novel theranostic agents for computed tomography imaging and photothermal/radiation synergistic therapy. ACS Appl Mater Interfaces, 2017, 9: 279-285

9 Long R, Zhou S, Wiley BJ, et al. Oxidative etching for controlled synthesis of metal nanocrystals: atomic addition and subtraction. Chem Soc Rev, 2014, 43: 6288-6310

10 Zheng Y, Zeng J, Ruditskiy A, et al. Oxidative etching and its role in manipulating the nucleation and growth of noble-metal nanocrystals. Chem Mater, 2013, 26: 22-33

11 Weng G, Dong X, Li J, et al. Halide ions can trigger the oxidative etching of gold nanorods with the iodide ions being the most efficient. J Mater Sci, 2016, 51: 7678-7690

12 Jiang Y, Zhu G, Lin F, et al. In situ study of oxidative etching of palladium nanocrystals by liquid cell electron microscopy. Nano Lett, 2014, 14: 3761-3765

13 Zou R, Guo X, Yang J, et al. Selective etching of gold nanorods by ferric chloride at room temperature. CrystEngComm, 2009, 11: 2797-2803

14 Wu J, Gao W, Yang H, et al. Dissolution kinetics of oxidative etching of cubic and icosahedral platinum nanoparticles revealed by in situ liquid transmission electron microscopy. ACS Nano, 2017, 11: 1696-1703

15 Hauwiller MR, Frechette LB, Jones MR, et al. Unraveling kinetically-driven mechanisms of gold nanocrystal shape transformations using graphene liquid cell electron microscopy. Nano Lett, 2018, 18: 5731-5737 
16 Ye X, Jones MR, Frechette LB, et al. Single-particle mapping of nonequilibrium nanocrystal transformations. Science, 2016, 354: 874-877

17 Ye X, Zheng C, Chen J, et al. Using binary surfactant mixtures to simultaneously improve the dimensional tunability and monodispersity in the seeded growth of gold nanorods. Nano Lett, 2013, 13: 765-771

18 Schneider NM, Norton MM, Mendel BJ, et al. Electron-water interactions and implications for liquid cell electron microscopy. J Phys Chem C, 2014, 118: 22373-22382

19 Xia Y, Xia X, Peng HC. Shape-controlled synthesis of colloidal metal nanocrystals: thermodynamic versus kinetic products. J Am Chem Soc, 2015, 137: 7947-7966

20 Tsung CK, Kou X, Shi Q, et al. Selective shortening of singlecrystalline gold nanorods by mild oxidation. J Am Chem Soc, 2006, 128: $5352-5353$

21 Kimura $\mathrm{Y}$, Niinomi H, Tsukamoto K, et al. In situ live observation of nucleation and dissolution of sodium chlorate nanoparticles by transmission electron microscopy. J Am Chem Soc, 2014, 136: 1762-1765

$22 \mathrm{Ni} \mathrm{W}$, Kou X, Yang Z, et al. Tailoring longitudinal surface plasmon wavelengths, scattering and absorption cross sections of gold nanorods. ACS Nano, 2008, 2: 677-686

23 Rodríguez-Fernández J, Pérez-Juste J, Mulvaney P, et al. Spatiallydirected oxidation of gold nanoparticles by $\mathrm{Au}(\mathrm{III})-\mathrm{CTAB}$ complexes. J Phys Chem B, 2005, 109: 14257-14261

24 Oda C, Walker C, Chino D, et al. Na-montmorillonite dissolution rate determined by varying the Gibbs free energy of reaction in a dispersed system and its application to a coagulated system in $0.3 \mathrm{M} \mathrm{NaOH}$ solution at $70^{\circ} \mathrm{C}$. Appl Clay Sci, 2014, 93-94: 62-71

25 Diedrich T, Dybowska A, Schott J, et al. The dissolution rates of $\mathrm{SiO}_{2}$ nanoparticles as a function of particle size. Environ Sci Technol, 2012, 46: 4909-4915

26 Grogan JM, Schneider NM, Ross FM, et al. Bubble and pattern formation in liquid induced by an electron beam. Nano Lett, 2014, 14: $359-364$

27 Loh ND, Sen S, Bosman M, et al. Multistep nucleation of nanocrystals in aqueous solution. Nat Chem, 2017, 9: 77-82

28 Tang L, Han B, Persson K, et al. Electrochemical stability of nanometer-scale Pt particles in acidic environments. J Am Chem Soc, 2009, 132: 596-600

29 Holby EF, Sheng W, Shao-Horn Y, et al. Pt nanoparticle stability in PEM fuel cells: influence of particle size distribution and crossover hydrogen. Energy Environ Sci, 2009, 2: 865-871

Acknowledgements This work was supported by the National Natural Science Foundation of China (51420105003, 11327901, 61601116 and 61974021), the National Science Fund for Distinguished Young Scholars (11525415), and China Scholarship Council (201806090114).

Author contributions The manuscript was written through contributions of all authors. All authors have given approval to the final version of the manuscript. Wang $\mathrm{W}, \mathrm{Xu} \mathrm{T}$, Zheng $\mathrm{H}$ and Sun $\mathrm{L}$ conceived and designed the experiments. Wang $\mathrm{W}$ carried out the in-situ TEM experiments, collected and analyzed the data; Xu T, Zhu C, Zhang Q took part in the discussion; Zhang HT and Zhang H took part in the data analysis; Guo $\mathrm{Z}$ and Bai $\mathrm{T}$ synthesized the samples; Sun L supervised the project and revised the paper with Zheng $\mathrm{H}$ and $\mathrm{Xu} \mathrm{T}$.

Conflict of interest The authors declare that they have no conflict of interest.

Supplementary information Supporting data and movies are available in the online version of the paper.

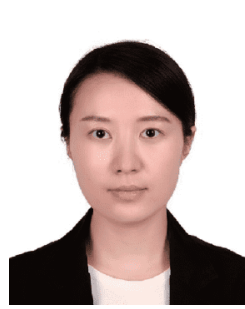

Wen Wang is a $\mathrm{PhD}$ candidate in Prof. Litao Sun's group at Southeast University. She is now a visiting student in Haimei Zheng's group at Lawrence Berkeley National Laboratory. She received her BE and master degree from the School of Physical Engineering, Zhengzhou University in 2013 and 2016, respectively. Her PhD research focuses on in-situ liquid cell TEM characterization.

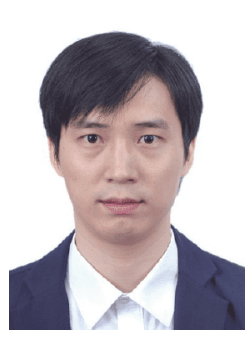

Tao Xu received his $\mathrm{PhD}$ degree from Southeast University in 2016. He did visiting research at Lawrence Berkeley National Laboratory during 2014-2015. He is currently an associate professor at Southeast University and his research interests focus on the structural evolution of nanomaterials under external stimuli (electron irradiation, thermal fields, electrical fields, etc.).

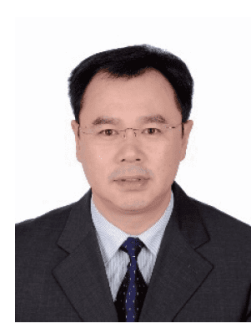

Litao Sun received his $\mathrm{PhD}$ from Shanghai Institute of Applied Physics, Chinese Academy of Sciences in 2005. He worked as a research fellow at the University of Mainz from 2005 to 2008, and a visiting professor at the University of Strasbourg from 2009 to 2010. He joined Southeast University as a Distinguished Professor in 2008. His work focuses on cutting-edge fundamental research and applications of nanomaterials in micro-nano system, renewable energy and environmental protection.

\section{金纳米棒可控刻蚀机制的原位液体环境透射电子 显微学研究}

王文 ${ }^{1,2}$, 徐涛 ${ }^{{ }^{*}}$, 柏婷婷 ${ }^{3}$, 朱超 ${ }^{1}$, 张秋波 ${ }^{1}$, 张弘韬, 张辉 ${ }^{1}$, 郭智点 ${ }^{3}$, 郑海梅, ${ }^{2,}$, 孙立涛 ${ }^{1 *}$

摘要 氧化性刻蚀是可控合成特定结构和性能的纳米材料的一种 重要手段. 揭示刻蚀机制和刻蚀过程中纳米材料的结构演变至关 重要. 我们利用原位液体环境透射电子显微学研究了金纳米棒在 不同电子束剂量率条件下的刻蚀行为: 情形I, $3.5 \times 10^{9} \mathrm{~Gy} \mathrm{~s}^{-1}$; 情形 II, $1.5 \times 10^{10} \mathrm{~Gy} \mathrm{~s}^{-1}$; 情形III, $4.5 \times 10^{10} \mathrm{~Gy} \mathrm{~s}^{-1}$. 根据电子束剂量率的不 同, 纳米棒尖端演变成稳定的低能量晶面(情形I)或逐步演变成椭 球形中间态并最终完全溶解(情形II). 更高剂量率下 (情形III), 金纳 米棒的快速刻蚀可能导致在纳米棒周围形成富含 $\mathrm{Au}^{3+}$ 离子的中间 态, 从而进一步加速横向刻蚀速率并显著增加纳米棒的长径比. 通 过定量分析表明, 纳米棒的临界尺寸会随着系统偏离平衡的程度 而变化, 在临界尺寸以下, 蚀刻速率会随着纳米棒尺寸的减小而显 著增加. 这些结果为氧化蚀刻机理提供了新的认识, 并为合理设计 和合成纳米结构提供了重要指导. 